University of Nebraska - Lincoln

DigitalCommons@University of Nebraska - Lincoln

Publications, Agencies and Staff of the U.S.

Department of Commerce

U.S. Department of Commerce

2011

\title{
Understanding and Estimating Effective Population Size for Practical Application in Marine Species Management
}

\author{
Matthew P. Hare \\ Cornell University, mph75@cornell.edu \\ Leonard Nunney \\ University of California - Riverside \\ Michael K. Schwartz \\ USDA Forest Service \\ Daniel E. Ruzzante \\ Dalhousie University \\ Martha Burford \\ Cornell University \\ See next page for additional authors
}

Follow this and additional works at: https://digitalcommons.unl.edu/usdeptcommercepub

Part of the Environmental Sciences Commons

Hare, Matthew P.; Nunney, Leonard; Schwartz, Michael K.; Ruzzante, Daniel E.; Burford, Martha; Waples, Robin S.; Ruegg, Kristen; and Palstra, Friso, "Understanding and Estimating Effective Population Size for Practical Application in Marine Species Management" (2011). Publications, Agencies and Staff of the U.S. Department of Commerce. 274.

https://digitalcommons.unl.edu/usdeptcommercepub/274

This Article is brought to you for free and open access by the U.S. Department of Commerce at DigitalCommons@University of Nebraska - Lincoln. It has been accepted for inclusion in Publications, Agencies and Staff of the U.S. Department of Commerce by an authorized administrator of DigitalCommons@University of Nebraska - Lincoln. 


\section{Authors}

Matthew P. Hare, Leonard Nunney, Michael K. Schwartz, Daniel E. Ruzzante, Martha Burford, Robin S. Waples, Kristen Ruegg, and Friso Palstra 


\title{
Understanding and Estimating Effective Population Size for Practical Application in Marine Species Management
}

\author{
MATTHEW P. HARE, ${ }^{*}$ LEONARD NUNNEY, $†$ MICHAEL K. SCHWARTZ, $\ddagger$ DANIEL E. RUZZANTE, $\S$ \\ MARTHA BURFORD,${ }^{* *}$ ROBIN S. WAPLES, $† \dagger$ KRISTEN RUEGG, $\neq \ddagger$ AND FRISO PALSTRA, $§ \S \#$ \\ *Department of Natural Resources, Cornell University, Ithaca NY 14853, U.S.A., email mph75@cornell.edu \\ †Department of Biology, 3306 Spieth Hall, University of California, Riverside, CA 92521, U.S.A. \\ ‡USDAForest Service, Rocky Mountain Research Station, 800 E. Beckwith Avenue, Missoula, MT 59801, U.S.A. \\ $\S$ Department of Biology, Dalhousie University, Halifax, Nova Scotia B3H 4J1, Canada \\ ${ }^{* *}$ Department of Natural Resources, Cornell University, Ithaca, NY 14853, U.S.A. \\ ††NOAA Fisheries, Northwest Fisheries Science Center, Seattle, WA 98112, U.S.A.

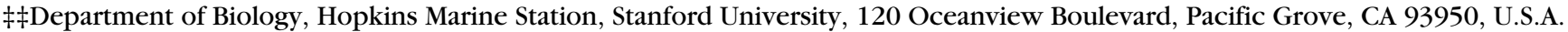 \\ $\S \S$ Department of Biology, Dalhousie University, Halifax, Nova Scotia B3H 4J1, Canada
}

\begin{abstract}
Effective population size $\left(\mathrm{N}_{\mathrm{e}}\right)$ determines the strength of genetic drift in a population and has long been recognized as an important parameter for evaluating conservation status and threats to genetic bealth of populations. Specifically, an estimate of $\mathrm{N}_{\mathrm{e}}$ is crucial to management because it integrates genetic effects with the life bistory of the species, allowing for predictions of a population's current and future viability. Nevertheless, compared with ecological and demographic parameters, $\mathrm{N}_{\mathrm{e}}$ has had limited influence on species management, beyond its application in very small populations. Recent developments bave substantially improved $\mathrm{N}_{\mathrm{e}}$ estimation; bowever, some obstacles remain for the practical application of $\mathrm{N}_{\mathrm{e}}$ estimates. For example, the need to define the spatial and temporal scale of measurement makes the concept complex and sometimes difficult to interpret. We reviewed approaches to estimation of $\mathrm{N}_{\mathrm{e}}$ over both long-term and contemporary time frames, clarifying their interpretations with respect to local populations and the global metapopulation. We describe multiple experimental factors affecting robustness of contemporary $\mathrm{N}_{\mathrm{e}}$ estimates and suggest that different sampling designs can be combined to compare largely independent measures of $\mathrm{N}_{\mathrm{e}}$ for improved confidence in the result. Large populations with moderate gene flow pose the greatest challenges to robust estimation of contemporary $\mathrm{N}_{\mathrm{e}}$ and require careful consideration of sampling and analysis to minimize estimator bias. We emphasize the practical utility of estimating $\mathrm{N}_{\mathrm{e}}$ by bighlighting its relevance to the adaptive potential of a population and describing applications in management of marine populations, where the focus is not always on critically endangered populations. Two cases discussed include the mechanisms generating $\mathrm{N}_{\mathrm{e}}$ estimates many orders of magnitude lower than census $\mathrm{N}$ in harvested marine fishes and the predicted reduction in $\mathrm{N}_{\mathrm{e}}$ from hatchery-based population supplementation.
\end{abstract}

Keywords: contemporary $N_{e}$, genetic drift, hatchery-based supplementation, inbreeding $N_{e}$, long-term $N_{e}$, metapopulation, $N_{e} / N$ ratio, selection, temporal method, variance $N_{e}$

Entendiendo y Estimando el Tamaño Poblacional Efectivo para Aplicación Práctica en el Manejo de Especies Marinas 
Resumen: El tamaño poblacional efectivo $\left(\mathrm{N}_{\mathrm{e}}\right)$ determina la fuerza de la deriva génica en una población y durante mucho tiempo ba sido reconocido como un parámetro importante para evaluar el estatus de conservación y las amenazas a la salud genética de las poblaciones. Específicamente, una estimación de $\mathrm{N}_{\mathrm{e}}$ es crucial para el manejo porque integra los efectos genéticos con la bistoria de vida de la especie, lo que permite predicciones de la viabilidad actual y futura de una población. Sin embargo, comparado con parámetros ecologicos y demográficos, $\mathrm{N}_{\mathrm{e}}$ ha tenido una influencia limitada sobre el manejo de especies, más allá de su aplicación en poblaciones muy pequeñas. Desarrollos recientes han mejorado sustancialmente la estimación de $\mathrm{N}_{\mathrm{e}}$; sin embargo, persisten algunos obstáculos para la aplicación práctica de las estimaciones de $\mathrm{N}_{\mathrm{e}}$, Por ejemplo, la necesidad de definir la escala espacial y temporal de la medida hace que el concepto sea complejo $y$ difícil de interpretar en algunas ocasiones. Revisamos los métodos de estimación de $\mathrm{N}_{\mathrm{e}}$ en marcos de tiempo a largo plazo y contemporáneos, clarificando sus interpretaciones con respecto a poblaciones locales y la metapoblación global. Describimos múltiples factores experimentales que afectan la robustez de las estimaciones contemporáneas de $\mathrm{N}_{\mathrm{e}}$ y sugerimos que se pueden combinar diferentes diseños de muestreo para comparar medidas marcadamente independientes de $\mathrm{N}_{\mathrm{e}}$ para una mejor confianza en el resultado. Poblaciones grandes con flujo génico moderado presentan el mayor reto para estimaciones de $\mathrm{N}_{\mathrm{e}}$ contemporánea y requieren de cuidadosas consideraciones de muestreo y análisis para minimizar el sesgo del estimador. Enfatizamos la utilidad práctica de la estimación de $\mathrm{N}_{\mathrm{e}}$ al resaltar su relevancia para el potencial adaptativo de una población y describiendo aplicaciones en el manejo de poblaciones marinas, en las que el enfoque no siempre ha sido sobre poblaciones en peligro crítico. Dos casos discutidos incluyen los mecanismos que generan estimaciones de $\mathrm{N}_{\mathrm{e}}$ muchos órdenes de magnitud por debajo de $\mathrm{N}$ censal en poblaciones de peces marinos explotados y la reducción de $\mathrm{N}_{\mathrm{e}}$ pronosticada en la suplementación de poblaciones a partir de criaderos.

Palabras Clave: deriva génica, metapoblación, método temporal, $N_{e}$ contempóranea, $N_{e}$ endogámica, $N_{e}$ varianza, proporción $N_{e} / N$ selección,suplementación basada en criaderos

\section{Introduction}

Populations of many species have declined due to anthropogenic factors. Effective management depends on an understanding of population ecology and genetics. In turn, this understanding requires robust information about population size and dynamics, distribution patterns and limits, reproductive strategy, and ability to adapt to abiotic and biotic changes. One parameter important to this process is the effective population size $\left(N_{e}\right)$, one of the fundamental parameters in evolutionary biology. Effective population size is also a crucial metric for management because it integrates the genetic effects of life history variation on microevolutionary processes. On the basis of estimates of contemporary $N_{e}$ one can predict a population's adaptive potential under environmental change as a function of vulnerability to genetic drift (stochastic forces).

The concept of $N_{e}$ was first introduced by Sewall Wright (1931), who defined it as the size of an imaginary, theoretically ideal population affected by genetic drift at the same rate per generation as the population being studied. This comparison with a theoretically ideal population standardizes measurement of genetic drift and makes $N_{e}$ comparable across populations with very different life histories. The theoretical ideal, referred to as a WrightFisher population, excludes factors (other than a constant population size) that increase genetic drift in real populations such as uneven sex ratio, population size fluctuations, and nonrandom variance in reproductive success. In this way, all factors contributing to genetic drift are re- duced to one variable, $N_{e}$, so that a small value indicates strong drift but does not identify the cause. For example, a population with many breeding individuals will have a small $N_{e}$ if the breeding system leads to a high variance in reproductive success. Census size is misleading about the strength of genetic drift, but the effective population size quantifies drift in a way that can be tracked over time or compared with any other population.

Genetic drift is an important evolutionary process with respect to conservation because the strength of stochastic genetic processes strongly influences how selection operates. As $N_{e}$ decreases, genetic drift erodes genetic variation, elevates the probability of fixation of deleterious alleles, and reduces the effectiveness of selection, all of which reduce overall fitness and limit adaptive responses. These genetic changes can drive a threatened population closer to extirpation, either directly (e.g., Saccheri et al. 1998; Madsen et al. 1999) or indirectly, through interactions with population dynamics that create an extinction vortex (Gilpin \& Soule 1986).

Understanding the consequences of random genetic changes that inevitably occur in all finite populations is central to identifying causes of population declines and formulating restoration and conservation goals. Legal mandates for conservation of species in the wild typically do not consider genetic factors explicitly (Laikre et al. 2010) and fail to include measurable management goals designed to maintain adaptive potential. Assessments of genetic diversity as indices of $N_{e}$ or adaptive potential have focused traditionally on allelic diversity or heterozygosity. These diversity indices reflect long-term or 
coalescent $N_{e}$ under mutation-drift equilibrium theory. They can be influenced strongly by the genetic effects of past demographic events, such as the legacy of reduced variation after a severe historical bottleneck, even if the population has expanded back to its original size. Longterm $N_{e}$ thus is not a reliable indicator of short-term or contemporary $N_{e}$ for a population, yet the contemporary magnitude of inbreeding and its trend is critical for estimating the probability of population persistence. Contemporary $N_{e}$ can best be approximated with recently developed analytical methods applied to genetic marker variation in one sample or a few samples taken over 2 or more generations. Although these short-term estimates may suggest management actions that help maintain larger $N_{e}$ in the near term, long-term estimates can provide a historical baseline for evaluating the realism of management targets.

In our review of recent developments in the estimation and application of $N_{e}$, we focused on genetic methods for estimating $N_{e}$ that have been made increasingly practical by recent advances in genotyping, software (Luikart et al. 2010), and computer processing speed. We have highlighted the potential application of $N_{e}$ to management of species in marine systems in order to expand consideration of $N_{e}$ to populations larger than those typically addressed by the small population paradigm (sensu Caughley 1984)

Traditionally, consideration of genetic factors affecting the probability of extinction focused primarily on $N_{e}$ in endangered species. Many harvested populations, especially in marine environments, occupy large areas and are often connected to others by high gene flow; features that lower a species' probability of extinction relative to more narrowly distributed species. Nonetheless, there are potential management benefits from estimating or monitoring $N_{e}$ of harvested populations. First, monitoring $N_{e}$ is valuable in the contexts of stock assessments, management of marine protected areas (MPAs), and hatchery-based enhancement of managed populations (Schwartz et al. 2007). In addition, in a species with population subdivision the relation between local (population) and global (species) $N_{e}$ can provide insights into patterns of connectivity among populations (e.g., Palstra et al. 2007; Waples 2010)—-knowledge that should help inform definitions of management units and MPAs. Second, the assumption that large marine populations are immune to detrimental effects of random genetic drift might be invalid in at least some cases. In most species, $N_{e}$ is $0.5-0.10$ the census population size $\left(N_{c}\right)$, but estimated $N_{e} / N_{c}$ ratios in marine species are often as low as $10^{-5}$ (Hauser \& Carvalho 2008; Palstra \& Ruzzante 2008). Thus, seemingly enormous populations may be more sensitive to genetic drift and inbreeding from intensive harvests than census sizes would suggest. Understanding what causes these extraordinarily low $N_{e} / N_{c}$ ratios is critical for predicting the effect of harvests. Third, marine-stock enhancement programs have been implemented for hundreds of species worldwide (Leber et al. 2004), and predicting the genetic effects of these programs on targeted natural populations requires knowledge of $N_{e}$ in both the hatchery and supplemented populations (Ryman \& Laikre 1991). Thus, assessments of $N_{e}$ in marine populations are important for routine as well as crisis management.

Our aim here was three-fold: to motivate a broader array of applications for estimates of $N_{e}$ and indicate how they can inform management; discuss the utility and interpretation of $N_{e}$ estimates with respect to temporal scale, spatial scale, and robustness; and highlight two contexts in which the magnitude of $N_{e}$ indicates possible genetic risks of common, demographically motivated management strategies applied to marine populations.

\section{Adaptive Potential Informed by $N_{e}$}

As $N_{e}$ declines, the balance between natural selection and genetic drift shifts, progressively favoring directionless changes in gene frequency driven by genetic drift over directed changes driven by selection. Wright (1931) showed that selection is ineffective if $N_{e} s \ll 1$, where $s$ is the selection coefficient defining the fitness differential between two alleles. If alleles at a locus satisfy this inequality, they behave as if they are effectively neutral (i.e., they have equivalent fitness consequences), in which case variants that would be slightly adaptive in a large population can more easily be lost by drift in a small population. Quantitative traits influence fitness through the action of many genes of small effect (adaptive variants with small $s$ ); thus, reduced $N_{e}$ can limit both single-locus and polygenic responses to selection (Willi et al. 2006). With large reductions in $N_{e}$, effective neutrality results in population-wide inbreeding depression due to the random spread and fixation at multiple loci of suboptimal alleles (Lynch \& Lande 1998; Charlesworth \& Willis 2009), which in turn can significantly increase the probability of population extirpation (Frankham 2005). This longterm process has been termed mutational meltdown because genetic drift over powers natural selection and leads to the accumulation of harmful mutations, which may subsequently further reduce population fitness and the probability of persistence (Lynch \& Gabriel 1990).

The relation between $N_{e}$ and selection is reciprocal. Although low $N_{e}$ increases the proportion of effectively neutral variants, strong directional selection reduces $N_{e}$ by increasing the variance in reproductive success among individuals. There is increasing evidence that intense directional selection on life-history traits, such as age and size at first reproduction, can result from commercial fishing (e.g., Olsen et al. 2004; Swain et al. 2007; Allendorf et al. 2008). In addition to the directional diversityreducing effects this selection will have at loci that 
contribute to life-history traits, such selection could substantially reduce $N_{e}$ and amplify random losses across the genome (Santiago \& Caballero 1995). To avoid this kind of genetic loss, it is important to maintain a relatively large global $N_{e}$ because loss of variation in a species can take a very long time to be reestablished through mutation. Even with quantitative traits, for which a polygenic basis produces an effective mutation rate orders of magnitude higher than single-locus traits (estimates vary widely), the mutational recovery of lost variation can be slow enough to limit the adaptive response to environmental change (Lynch \& Lande 1998; Willi et al. 2006).

\section{Estimating $N_{e}$ at Long and Short Time Scales}

One of the strengths of $N_{e}$ estimation is flexibility of temporal and spatial scale (Crandall et al. 1999), but with flexibility comes the challenge of sampling properly and choosing appropriate $N_{e}$ estimators for each management goal. Currently, long-term coalescent (Kuhner 2006), contemporary-single time point (Hill 1981; Waples 1991), and contemporary-temporal (Nei \& Tajima 1981) methods are the most widely used for estimating $N_{e}$. Whereas contemporary measures estimate $N_{e}$ over the time samples were collected (Fig. 1a), the coalescent method estimates $N_{e}$ integrated over many generations since the most recent common ancestor (Fig. 1b). In either case, when $N_{e}$ fluctuates over time, population bottlenecks have a more lasting effect than expansions because genetic diversity lost at small $N_{e}$ will only be recovered through the slow processes of mutation or gene flow. Thus, at estimation scales longer than a single time point, $N_{e}$ estimates are a harmonic mean over time (greater weighting of small values).

\section{Long-Term Estimates of $N_{e}$}

Coalescent estimates of $N_{e}$ are used if the goal is to understand the long-term $N_{e}$ of a species prior to contemporary influences such as intensive harvesting or climate change (Whiteley et al. 2010). Long-term estimates of $N_{e}$ require only a single random sample of individuals and are derived from the equilibrium prediction that a measure of genetic diversity $(\theta)$ will vary as a joint function of $N_{e}$ and average mutation rate $\mu$ : $\theta=4 N_{e} \mu$. Estimates of $\theta$ can be made from summary statistics such as heterozygosity or pairwise sequence divergence, but coalescent methods involving computationally intensive genealogy simulations are generally preferred because they can account for genealogical uncertainty as well as confounding processes such as gene flow or changes in abundance (Heled \& Drummond 2008; Kuhner 2009). Nevertheless, different parts of a genome can have significantly different histories of selection and mutation; thus, estimates should be based on sampling multiple loci. Although the ideal infer- ence of historical $N_{e}$ for most management applications would target the period just prior to human intervention, long-term estimates of $N_{e}$ represent the weighted harmonic mean of $N_{e}$ over a substantial period of about $4 N_{e}$ generations (e.g., if $N_{e}=1000$, up to 4000 generations), with greater weight on more recent generations (Beerli 2009). Technically, long-term estimates represent "inbreeding $N_{e}$," or the rate of change in inbreeding over time. Also, unlike methods to estimate contemporary $N_{e}$, long-term estimates of $N_{e}$ depend on the mutation rate at the loci being studied, which is rarely known with much certainty.

In some cases long-term estimates of $N_{e}$ can indicate population size prior to harvest, which may suggest how species responded to harvests and inform establishment of recovery goals (Alter et al. 2007; Ruegg et al. 2010). For example, Alter et al. (2007) used coalescent estimates of $N_{e}$ to approximate the census size of Pacific gray whales (Eschrichtius robustus) prior to intensive harvesting in the early 1900s. The long-term $N_{c}$ estimate of approximately 96,000 individuals was 3-5 times larger than modern survey-based estimates of approximately 22,000 individuals, which suggests populations are currently much smaller than in the past. If the estimated abundance before whaling were used to inform management under current policies, it would decrease the sustainable humancaused mortality calculated for eastern gray whales from 417 to 208 individuals per year. Alternative coalescent methods have been used on other taxa to examine the evolutionary history of $N_{e}$ in association with environmental change (Garrigan et al. 2002; Shapiro et al. 2004; Ruzzante et al. 2008).

\section{Estimating $N_{e}$ Over Contemporary Timescales}

Contemporary estimates of $N_{e}$ (either 1- or 2-sample estimators; Fig. 1) can be useful for evaluating existing adaptive potential or monitoring changes in the strength of genetic drift. Most $N_{e}$ estimation methods assume discrete generations and produce a per-generation estimate; however, in species with overlapping generations, it is difficult to define (and challenging to collect) a random sample from an entire generation. Instead, short-term methods applied to a sample of same-aged juveniles will estimate a related parameter, $N_{b}$, effective number of breeders in a single year (Fig. 1a). These two parameters are approximately related as $N_{e} \approx$ generation length $*$ $N_{b}$, provided that iteroparity is low. There is little empirical information on how estimates of $N_{b}$ relate to $N_{e}$ per generation in age-structured populations and how this relation varies as a function of the species' life history and sampling design. It is clear, however, that $N_{e}$ and $N_{b}$ can be quite different properties, especially in long-lived organisms, and it is essential to specify to what time period a genetic estimate of $N_{e}$ precisely refers to (cf. Waples 2005). 
(a)

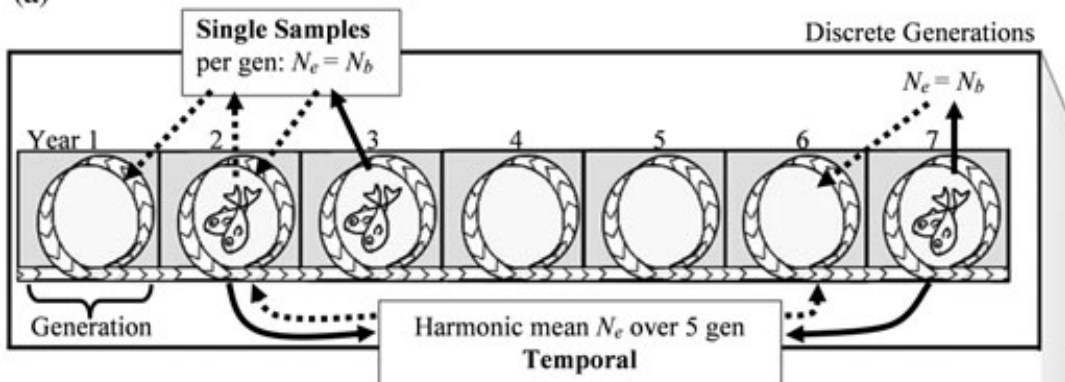

(b)

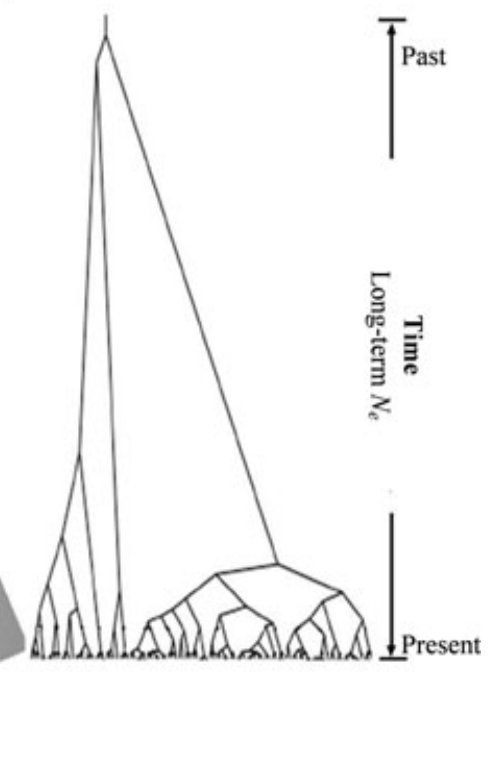

Figure 1. Time intervals over which (a) contemporary and (b) long-term $\mathrm{N}_{\mathrm{e}}$ (effective population size) estimates apply. In (a) brackets demarcate generations and loops depict single-year breeding cycles under discreet (top) or overlapping (bottom) generations. For both single-sample estimates of inbreeding $\mathrm{N}_{\mathrm{e}}$ and temporal methods of estimating variance $\mathrm{N}_{\mathrm{e}}$, solid arrows link a sample (depicted as fishes) with the parameter being estimated; dashed arrows indicate the year(s) for which the estimate pertains. Each sample is assumed to be from a single cobort before reproduction. In the discreet-generation case both single-sample and temporal metbods provide an estimate of $\mathrm{N}_{\mathrm{e}}$ per generation (gen). In (b) the time scale of long-term $\mathrm{N}_{\mathrm{e}}$ estimates is defined by the time to the most recent common ancestor in the coalescent genealogy relating sampled gene copies.

The temporal method estimates the harmonic mean $N_{e}$ over time on the basis of allele frequency differences across two or more temporal samples from the same population, after accounting for sampling error. This method specifically estimates "variance $N_{e}$," so-named because it reflects allele frequency variance generated by genetic drift, as opposed to "inbreeding $N_{e}$," although similar values are expected under constant population size (Crow \& Denniston 1988). Estimate precision increases and potential bias associated with overlapping generations decreases as the number of drift episodes (generations between samples) increases (Waples \& Yokota 2007). Thus, archived samples can be valuable, as was shown in a study addressing declines in abundance of Atlantic salmon (Salmo salar) in Newfoundland that prompted the 1992 closure of the commercial fishery. Palstra et al. (2009) applied the temporal method with archived samples collected over nearly 60 years to estimate effective population sizes and concluded that $N_{e}$ likely increased in some small populations following the fishery closure. The temporal method has been applied to a number of other managed fish species, including different populations of cod (Gadus morbua) (Hutchinson et al. 2003; Poulsen et al. 2006), the endangered North Sea houting (Coregonus oxyrbynchus) (Hansen et al. 2006), New Zealand snapper (Pagrus auratus) (Hauser et al.
2002), and flatfish (Pleuronectes platessa) (Hoarau et al. 2005).

Multiple methods have been proposed for singlesample estimation of contemporary $N_{e}$ (Wang 2005), and continuing development of these methods shows great promise (e.g., Tallmon et al. 2008; Wang 2009). Singlesample methods estimate $N_{e}$ from genetic patterns within a single population sample on the basis of patterns of heterozygosity, linkage disequilibrium, or individual relatedness. These methods are useful because one does not need to wait several generations (which can be on the order of decades for long-lived species) for a second sampling before estimating $N_{e}$. Furthermore, simulations suggest that these methods often can detect population trends as accurately as classical ecological methods (Tallmon et al. 2010). In general, single-sample methods estimate inbreeding $N_{e}$ in the generation preceding the sample by measuring the genetic result of processes acting in the parental generation (Fig. 1). For example, correlations among alleles at different loci are not expected at unlinked loci in an infinitely large ideal population, but a finite number of breeders generate random allelic correlations in offspring, commonly referred to as linkage disequilibrium, that increase as $N_{e}$ decreases (Hill 1981). Alternatively, $N_{e}$ can be estimated from excess heterozygosity in a sample relative to Hardy-Weinberg 
expectations (Pudovkin et al. 1996) or from estimated frequencies of half and full siblings on the basis of multilocus genotypes in a cohort sample (Wang 2009).

Portnoy et al. (2009) used both the single-sample linkage-disequilibrium method and the temporal method to estimate the contemporary $N_{e}$ of heavily fished populations of western Atlantic sandbar sharks (Carcharbinus plumbeus). Within each of two vital inshore nursery habitats, they estimated annual $N_{b}$ within cohorts and compared these estimates with $N_{e}$ estimated across cohorts. Estimates from the two methods were in good agreement (both approximately $50 \%$ of census $N$ ) and suggested that $N_{e}$ and $N_{b}$ in sandbar sharks are currently above levels at which adaptive potential would be decreasing. The magnitude of $N_{e}$, however, appeared to be strongly coupled with, and roughly half the size of, $N_{c}$. Therefore, further declines in abundance might directly reduce $N_{e}$.

\section{Connections between Temporal and Spatial Scales of $N_{e}$}

Long-term versus contemporary methods are often used to estimate $N_{e}$ at the species-level and local population levels, respectively. Most local populations are not completely isolated, however. Rather, they exist as part of a metapopulation connected by regular or episodic gene flow. The classical definition of a metapopulation (Levins 1969) is a network of local populations that exchange migrants, but have somewhat independent demography with frequent extinction and recolonization. Nevertheless, a wide range of metapopulation-model variants have also been considered, including Wright's island model, in which subpopulations are fixed in size and exchange migrants symmetrically at a constant rate. Metapopulation processes make the spatial distinction between long-term (global) and contemporary (local) $N_{e}$ more ambiguous, so joint consideration of spatial and temporal processes is important (Whitlock \& Barton 1997; Nunney 1999).

To illustrate how spatial and temporal aspects of $N_{e}$ are related, we used simulations to graph heterozygosity (as a surrogate for long-term $N_{e}$ ) for samples collected at the local (population) and global (metapopulation) scales (Fig. 2). With complete population isolation, local $N_{e}$ is much smaller than metapopulation $N_{e}$, and each population contains only a small fraction of the total genetic diversity $\left(H_{t}\right)$. Nonetheless, little gene flow (1 migrant per generation in an island model) is needed to ensure that local populations share most of the genetic diversity in the metapopulation. So, over long periods, metapopulation processes are extremely effective in spreading genetic diversity among populations.

Long-term estimates of $N_{e}$ can be misleading if they do not properly account for metapopulation processes. Two types of errors are possible (Fig. 2). If populations
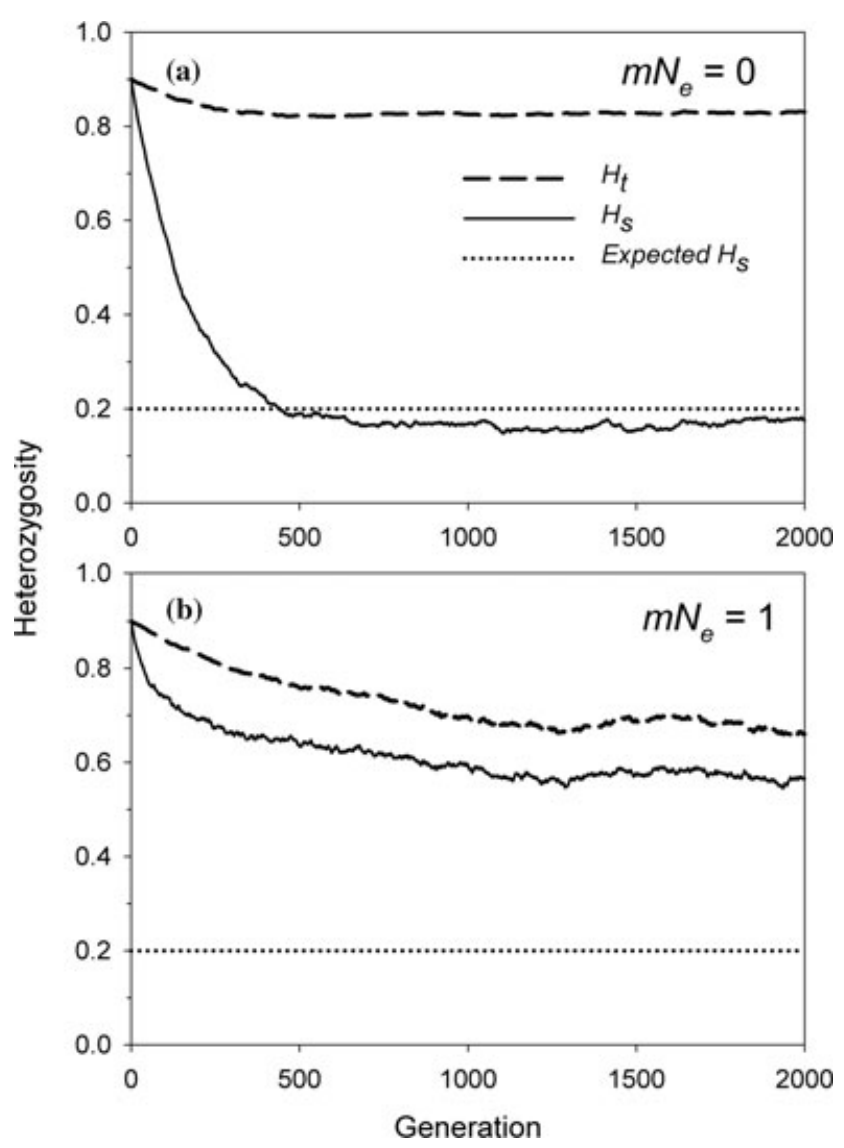

Figure 2. Simulated relation between mean within-population expected beterozygosity $\left(\mathrm{H}_{\mathrm{s}}\right)$ and expected beterozygosity for a metapopulation $\left(\mathrm{H}_{\mathrm{t}}\right)$ as a function of level of gene flow in a (a) completely isolated population and (b) populations with a modest amount of migration $\left(\mathrm{mN}_{\mathrm{e}}: \mathrm{m}\right.$, proportion of migrants per generation; $\mathrm{N}_{\mathrm{e}}$, long-term effective size per generation) and time since initialization (dotted line, expected $\mathrm{H}_{\mathrm{s}}$ for a local population without gene flow; solid and dashed curve, results using EasyPop [Balloux 2001] to simulate four constant size, randomly mating populations of 100 individuals each in an island model [i.e., constant and symmetric gene flow]). In this simulation, each of 20 neutral gene loci bad a maximum of 10 allelic states and a mutation rate of $5 \times 10^{-4}$ and the first generation was initiated with the "maximal diversity" option (Waples 2010).

are completely isolated, local sampling will substantially underestimate long-term global $N_{e}$ of the metapopulation (Fig. 2a), but with even a modest amount of migration an estimate of long-term $N_{e}$ derived from only local sampling will not be highly biased (i.e., $H_{s}$ much closer to $H_{t}$; Fig. 2b). Conversely, if one is interested in estimating the long-term $N_{e}$ of a local population, the resulting estimate will be accurate only for populations that are nearly or completely isolated. Otherwise, a long-term method 
will produce an estimate that is closer to the global $N_{e}$ of the entire metapopulation (e.g., in Fig. 2b with $m$ $N_{e}=1$, or one migrant per generation; $H_{s}$ is much higher than the value in Fig. $2 \mathrm{a}$ for an isolated population with $N_{e}=100$ ).

In Wright's (1943) island model, total genetic diversity is higher when populations are completely isolated than when individuals migrate among populations (Fig. 2). This occurs because in this model, populations are equal and fixed in size. If populations are isolated, different alleles by chance drift to fixation in different populations, which effectively arrests genetic diversity for the metapopulation as a whole at a level that normally would be found only in a much larger population. Consequently, in Wright's island model the global $N_{e}$ is greater than the sum of the local $N_{e}$ values ( $\sum$ local $N_{e}$ ). Under most other (arguably more realistic) models, which can include extirpation or recolonization of populations, fluctuations in population size, and unequal population growth rates, the opposite result generally holds: global $N_{e}<\sum$ local $N_{e}$ (global $N_{e}$ may even be a great deal smaller) (Nunney 1999; Wang \& Caballero 1999; Wares \& Pringle 2008). Thus, the global $N_{e}$ of the metapopulation can be either larger or smaller than $\sum$ local $N_{e}$, depending on various demographic processes, and estimates at both global and local scales help decipher metapopulation processes.

Management efforts often incorporate information on recent $N_{e}$ in local populations, in which case contemporary $N_{e}$ estimators are most appropriate. Because these methods typically assume closed populations, evaluating sensitivity of $N_{e}$ estimates to migration sheds light on the relative importance of local population versus global metapopulation processes in shaping contemporary $N_{e}$. Unpublished simulation data show that the single-sample method based on linkage disequilibrium produces an estimate that is much closer to local $N_{e}$ than to metapopulation $N_{e}$ unless migration rate is relatively high in genetic terms ( $m>10 \%$ generally, or 10 times higher than shown in Fig. 2b) (P. England and R. Waples, unpublished data). A similar result applies to the standard (2-sample) temporal method (G. Luikart, unpublished data), provided the samples are not spaced too far apart in time. These results mean that over 5-10 generations, unless migration rate is high, random processes of genetic drift are driven more by local $N_{e}$ than global $N_{e}$. This in turn means that estimators of contemporary $N_{e}$ can provide useful information about population demography at local scales.

\section{Robustness of Contemporary $N_{e}$ Estimates}

Understanding the biological significance of contemporary $N_{e}$ estimates will be facilitated in cases where possible sources of error can be evaluated to assess the degree of bias (accuracy) and repeatability (precision)

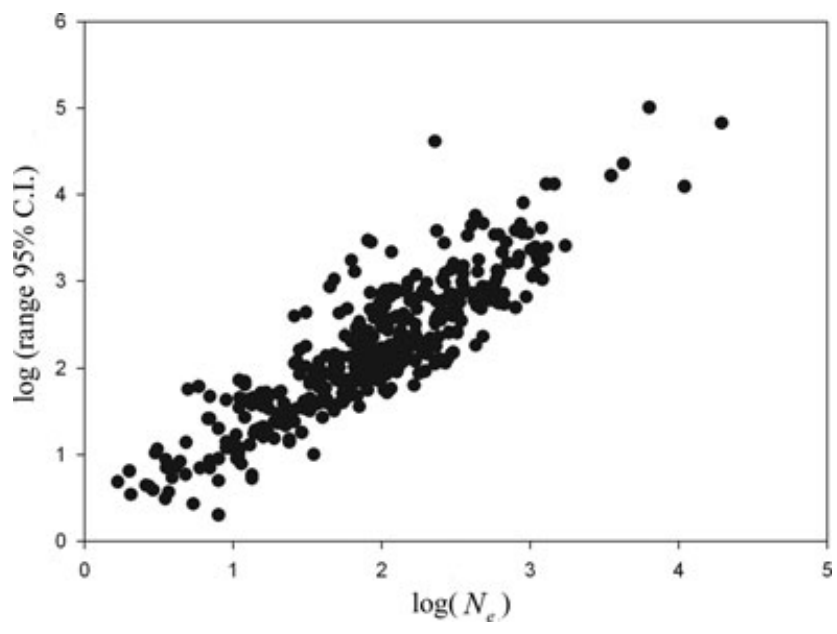

Figure 3. Precision as a function of the magnitude of empirical point estimates for contemporary $\mathrm{N}_{\mathrm{e}}$ (effective population size) (Palstra \& Ruzzante 2008). Only estimates with finite upper confidence limits are included, so the observed relation is biased toward better precision at higher $\mathrm{N}_{\mathrm{e}}$.

of an estimate. For local $N_{e}$ estimates these sources include sampling error contributing to wide confidence intervals; upward or downward bias caused by gene flow (Wang \& Whitlock 2003; Waples \& Do 2010); or downward bias from insufficient sampling, unrepresentative sampling (i.e., uneven age structure composition in the sample), or technical errors (Palstra \& Ruzzante 2008). Efforts should be made to minimize each of these biases, but whether those efforts are successful is difficult to evaluate in single empirical studies (but see England et al. 2006). Instead, although not statistically justified, precision is commonly used as a proxy for estimate accuracy, as reflected first by whether a finite point estimate and upper confidence limit are achieved, and if so, by the breadth of the confidence interval. All genetic methods that estimate $N_{e}$ in diploid organisms measure a signal (e.g., inbreeding, drift) that gets vanishingly small in larger populations (i.e., scales to $1 /\left[2 N_{e}\right]$ ). It is therefore to be expected that the variance of most $N_{e}$ estimators increases (exponentially) as the mean value increases (Hill 1981; Pollak 1983), a result illustrated by the estimated error around published estimates of $N_{e}$ (Fig. 3) (Palstra \& Ruzzante 2008). One will need to determine whether achievable precision is sufficient for a given set of objectives (Berthier et al. 2002).

Unfortunately, when actual $N_{e}$ is very large, systemic evolutionary forces other than drift, such as selection and gene flow, will have relatively greater confounding influences on estimated $N_{e}$. Currently no practical models exist to evaluate the combined effects of all evolutionary forces on $N_{e}$. The weak drift signal in large populations also amplifies the effects of technical mistakes, random 
sampling error, and biases from nonrandom sampling on estimates of $N_{e}$. We focused on considerations of sample size, age structure, and metapopulation structure. Stratifying sampling across the latter 2 factors can reduce bias by making empirical estimates explicit with regards to temporal and spatial reference points.

\section{Sample Size and Precision}

To some extent, precision and accuracy of large $N_{e}$ estimates can be improved by increasing sampling efforts for both individuals and loci (Waples 1989; Berthier et al. 2002; Wang 2009). Luikart et al. (2010) report that precision can be improved more by doubling the number of individuals sampled than by doubling the number of loci. Sampling might have to be intensive to obtain sufficient power for a finite point estimate of $N_{e}$ when true effective size is large (e.g., $N_{e}$ estimate range of 797-1304 for a local population of estuarine shrimp (Penaeus escullentus) (Ovenden et al. 2007; Waples \& Do 2010). As a rough guideline for sampling requirements in empirical studies, Palstra and Ruzzante (2008) suggest that at least $10 \%$ of a population's effective size may need to be sampled. Given practical constraints, larger samples need to be carefully weighed against improvements in precision that can be attained from increasing the number of marker loci, marker diversity, or the sampling interval for temporal $N_{e}$ (Waples 1989; Palstra \& Ruzzante 2008; Waples \& Do 2010). Consideration of which estimators to use can also be relevant because the relative precision of methods can differ depending on sampling design (Wang 2009; Waples \& Do 2010).

In marine populations with large effective size, confidence intervals can be strongly asymmetrical (Fig. 4); the distance from the point estimate to the upper bound can be infinite or much larger than the distance to the lower bound. Even with an infinite upper confidence limit, however, the lower confidence limit on an unbiased point estimate can be a useful indicator of the lowest possible level of $N_{e}$ (Fraser et al. 2007).

Although precision can be low for large populations, for example too low to statistically distinguish $N_{e}$ estimates of moderate (500) and large size (5000), independent genetic estimators of $N_{e}$ provide the opportunity to assess accuracy through convergence of estimators. For example, "variance $N_{e}$ " estimated by temporal methods and "inbreeding $N_{e}$ " estimated from single-sample linkage disequilibrium provide independent estimates of $N_{e}$ (Waples 1991). Also, because inbreeding $N_{e}$ estimates apply to the parents and grandparents of the sampled individuals they are time lagged relative to variance $N_{e}$ (Fig. 1a) and will behave differently in increasing and decreasing populations (Crow \& Denniston 1988). Given the predictability of demographic effects on inbreeding and variance $N_{e}$, the slightly different way that these two metrics reflect the drift process can be an advantage

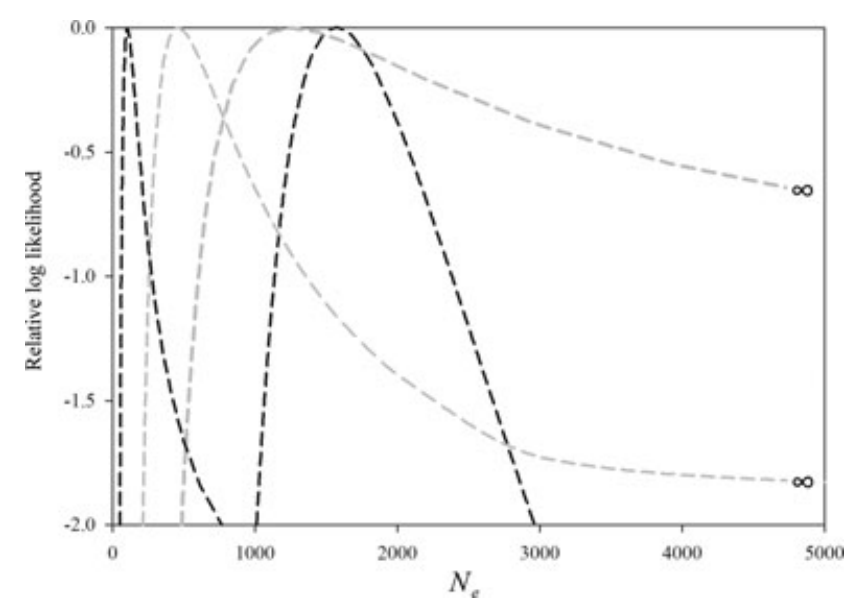

Figure 4. Pseudo-maximum likelibood profiles of variance $\mathrm{N}_{\mathrm{e}}$ (effective population size) estimates calculated using the method of Wang (2001) with temporal genetic data (13 microsatellites) for Atlantic salmon from four rivers (F. Palstra, unpublished data). In these examples, a relative log-likelihood value of zero corresponds to the point estimate of $\mathrm{N}_{\mathrm{e}}$ and a value of -2 corresponds to the outer limits of the 95\% CIs (black, two estimates with finite confidence limits; grey, two estimates with infinite upper confidence limits).

that further argues for their comparison (e.g., Shrimpton \& Heath 2003; Hedgecock et al. 2007; Palstra et al. 2009). For example, Portnoy et al. (2009) report a relative consistency among $N_{e}$ estimates from the temporal and linkage-disequilibrium methods for sandbar sharks, with the roughly 1.5 - to 3 -fold difference attributable to inference over different timeframes. In addition to comparing independent estimators, empirical estimates from different methods can sometimes be combined to generate a more precise overall $N_{e}$ estimate (Waples \& Do 2010)

\section{Demographically Stratified Sampling}

Although the majority of genetic theory on which estimates of $N_{e}$ are based assumes discrete generations, most marine organisms have age structure (overlapping generations). Ignoring age structure in empirical studies can bias estimates of $N_{e}$. The bias imposed by age structure is best documented for the temporal method (Jorde \& Ryman 1995; Waples \& Yokota 2007), where, generally, it seems to lower $N_{e}$ over time scales relevant to conservation and management (Palstra \& Ruzzante 2008). One option to avoid this bias is to collect age information and, where possible, reconstruct cohorts, which facilitates an estimation of $N_{b}$, Linking $N_{b}$ to $N_{e}$ remains challenging, however, especially in organisms characterized by iteroparity. Without cohort information, empirical estimates will often correspond to a quantity somewhere 
between $N_{b}$ and $N_{e}$, and management actions should take into account this uncertainty (Waples 2005).

\section{Marine Fisheries Management Challenges Related to $N_{e}$}

\section{Extremely Low Contemporary $N_{e} / N_{c}$}

Theory suggests that $N_{e} / N_{c}$ ratios in the wild should be $\geq 0.1$ (Nunney \& Campbell 1993; Frankham 1995; Vucetich et al. 1997), and empirical evidence for most species and populations is largely consistent with this prediction (Frankham 1995; Palstra \& Ruzzante 2008). Managing a population with a typical $N_{e} / N_{c}$ ratio results in similar goals whether based on ecological or genetic principles (Nunney \& Campbell 1993). For example, if a large marine population has been reduced from $N_{c}=10^{7}$ to $N_{c}=10^{5}$ by harvest, genetic drift is not much of a concern if $N_{e} / N_{c}=0.1$ (because $N_{e}$ would still be approximately $10^{4}$ ). In contrast, exceptionally low $N_{e} / N_{c}$ ratios of $10^{-3}-10^{-5}$ have been estimated for some very abundant and widely distributed marine fish species that are harvested (e.g., New Zealand snapper [P. auratus], Hauser et al. 2002; plaice $[P$. platessa], Hoarau et al. 2005). In these cases, if demographic processes are maintaining the extreme ratio, then genetic management requires the maintenance of a much larger census size than would typically be recommended on the basis of information about population dynamics.

The effects of these especially low $N_{e} / N_{c}$ ratios on achieving conservation objectives depend partly on underlying mechanisms causing the pattern. To narrow the range of plausible mechanism hypotheses it will be important to estimate $N_{e}$ with studies designed to minimize the potential for underestimation of $N_{e}$ in abundant, longlived, iteroparous species with overlapping generations. Two recent studies in which the temporal method was used to estimate contemporary $N_{e}$ in marine organisms attempted to minimize bias either by considering cohorts (Saillant \& Gold 2006) or by examining a species with discrete generations (Ovenden et al. 2007). Both studies estimated $N_{e} / N_{c} \approx 10^{-3}$, a ratio that, although still two orders of magnitude smaller than 0.1, would place $N_{e}$ estimates for most marine organisms in the thousands instead of hundreds, further from population sizes where genetic drift is a practical concern.

There might be no single mechanism driving extremely low $N_{e} / N_{c}$ ratios (Turner et al. 2006), although high fecundity and high juvenile mortality (type III survivorship curve) are widely hypothesized to be necessary. The importance of hypothesized alternative mechanisms, such as selective harvests (Saillant \& Gold 2006; Turner et al. 2006), has been difficult to evaluate, however, because few studies have examined $N_{e} / N_{c}$ ratios in unharvested taxa with very large population sizes. One exception is an unharvested population of the marine macroalga $\mathrm{Fu}$ cus serratus, in which the $N_{e} / N_{c}$ ratio was estimated to be $10^{-3}-10^{-4}$ (Coyer et al. 2008), suggesting that harvest is not a necessary condition leading to extremely small ratios. The idea that strong selection from harvest could exacerbate $N_{e} / N_{c}$ skew is supported by modeling of within-host populations of HIV-1. The models show that, at least in extreme cases, strong selection significantly lowers $N_{e} / N_{c}$ ratios (Liu \& Mittler 2008). Thus, natural selection or selective harvesting can lower $N_{e}$ relative to $N_{c}$ in some cases, but in general much is still unknown about the relative strength of extrinsic mechanisms that potentially enhance variance in reproductive success among individuals or demes (Turner et al. 2006).

\section{Hatchery-Based Supportive Breeding}

Some management procedures pose risks to genetic diversity in proportion to the $N_{e}$ of the target population. Supportive breeding has become a common practice for the routine management and restoration of harvested aquatic species. Supportive breeding entails production of many juveniles from relatively few brood stock for release into the wild to rapidly increase census population size. Perhaps counter intuitively, this procedure has a greater potential to increase inbreeding when supplemented populations have large $N_{e}$ (Ryman \& Laikre 1991).

Typically, supportive breeding amplifies overall variance in reproductive success relative to the case in which there is no supplementation, resulting in lowered $N_{e T}$ (effective size of the entire captive-wild system after supplementation). The $N_{e T}$ for a single generation of supportive breeding is expected to be a function of effective sizes of the wild presupplementation and captive-born stocked components $\left(N_{e W}, N_{e C}\right)$ and the fractional contribution $(x)$ of cultured individuals that mature in the wild and mate randomly relative to the total number of breeders (Ryman \& Laikre 1991):

$$
N_{e_{T}}=\frac{1}{\frac{x^{2}}{N_{e_{C}}}+\frac{(1-x)^{2}}{N_{e_{W}}}} .
$$

Two effects of hatchery-based supplementation are worth highlighting (Fig. 5). First, for any captive fraction $(x)$ and a realistic range of $N_{e C}, N_{e T}$ will be dramatically reduced relative to $N_{e W}$ when $N_{e W}$ is high, but singlegeneration effects are more moderate when $N_{e W}$ is already low. Second, smaller captive fractions will elevate the curves described by (Eq. 1) so that a wider set of conditions maintain presupplementation levels of $N_{e W}$. Nevertheless, most supplementation programs attempt to maximize hatchery contributions (increase $x$ ) to increase population size, so demographic goals conflict with the goal of maintaining large $N_{e}$. Furthermore, (Eq. 1) does not adjust $N_{e W}$ for the removal of individuals to the 


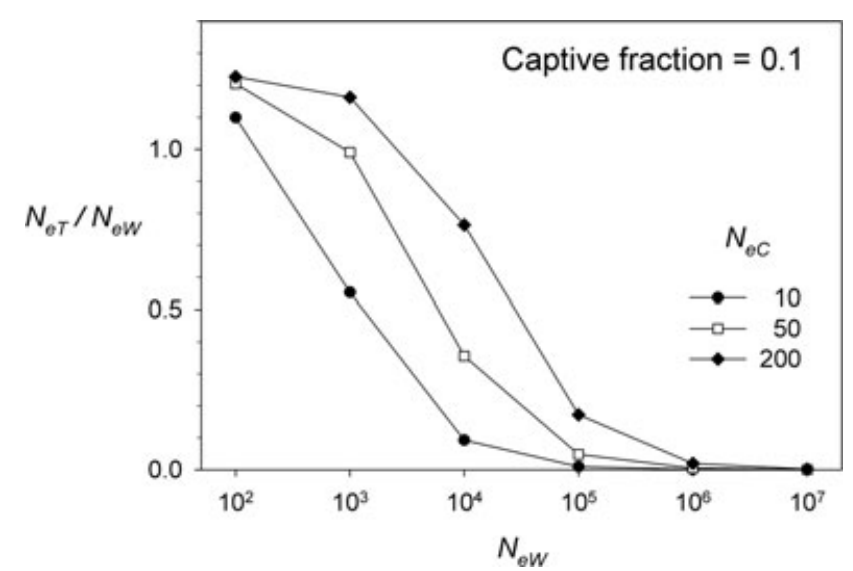

Figure 5. Effects of a single generation of supportive breeding on $\mathrm{N}_{\mathrm{e}}$ based on Eq. 1 ( $\mathrm{N}_{\mathrm{e}}$, total effective population size; $\mathrm{N}_{\mathrm{eW}}$, presupplementation effective population size; $\mathrm{N}_{\mathrm{eC}}$, effective population size in the batchery; captive fraction, proportion of individuals successfully reproducing in the wild that were produced in the batchery).

hatchery for captive breeding; the positive effects $\left(N_{e T} / N_{e W}>1\right.$, y-axis $)$ depicted at low $N_{e W}$ in Fig. 5 are an artifact of this approximation. Thus, the best result that can be expected is $N_{e T} / N_{e W}=1$ (no change in $N_{e W}$ ) unless brood stock contributions are equalized in the hatchery to increase $N_{e C}$ relative to the number of captive breeders, thereby decreasing genetic supplementation effects.

Factors that ameliorate or exacerbate this RymanLaikre effect have been examined (Waples \& Do 1994; Wang \& Ryman 2001; Hansen \& Jensen 2005), and this examination has led to general recommendations for minimizing the effect (Hedrick et al. 2000; Miller \& Kapuscinski 2003; Camara \& Vadopalas 2009). Few data are available to test the long-term efficacy of hatchery-based enhancement (Araki et al. 2007, 2009). Of dozens of marine species with large hatchery supplementation programs, Hedgecock and Coykendall (2007) found only two cases in which all four Ryman-Laikre parameters (Eq. 1) had been estimated to evaluate the potential for reduction of $N_{e}$ as a result of supportive breeding. The probability that a hatchery-based supplementation program will increase inbreeding in the target populations can be assessed by defining goals in terms of fractional contribution per generation and measuring the difference between $N_{e C}$ and local contemporary $N_{e W}$. Because the upper confidence limit on $N_{e W}$ estimates will often be infinite for large populations, it may be impossible to quantify the maximum possible inbreeding increase for a given supplementation plan. Instead, to evaluate natural heterogeneity and the spatial scales at which gene flow could ameliorate genetic consequences of supportive breeding, the best practical focus may be determi- nation of finite estimates of $N_{e}$ and its variability across temporal and spatial samples.

\section{Acknowledgments}

We benefited from helpful comments on earlier drafts by E. Main, M. Hunter, and three anonymous reviewers. This review was inspired by a symposium on the same topic at the International Marine Conservation Congress of 2009. This work was supported in part by National Science Foundation Oce-0648528 (to M.P.H.).

\section{Literature Cited}

Allendorf, F. W, P. R. England, G. Luikart, P. A. Ritchie, and N. Ryman. 2008. Genetic effects of harvest on wild animal populations. Trends in Ecology \& Evolution 23:327-337.

Alter, S. E., E. Rynes, and S. R. Palumbi. 2007. DNA evidence for historic population size and past ecosystem impacts of gray whales. Proceedings of the National Academy of Sciences 104:1516215167.

Araki, H., B. Cooper, and M. S. Blouin. 2007. Genetic effects of captive breeding cause a rapid, cumulative fitness decline in the wild. Science 318:100-103.

Araki, H., B. Cooper, and M. S. Blouin. 2009. Carry-over effect of captive breeding reduces reproductive fitness of wild-born descendents $n$ the wild. Biology Letters 5:621-624.

Balloux, F. 2001. EASYPOP (version 1.7): a computer program for population genetics simulations. Journal of Heredity 92:301-302.

Beerli, P. 2009. How to use MIGRATE or why are Markov chain Monte Carlo programs difficult to use? Pages 42-79 in G. Bertorelle, M. W. Bruford, H. C. Hauffe, A. Rizzoli, and C. Vernesi, editors. Population genetics for animal conservation. Cambridge University Press, Cambridge, United Kingdom.

Berthier, P., M. A. Beaumont, J. M. Cornuet, and G. Luikart. 2002. Likelihood-based estimation of the effective population size using temporal changes in allele frequencies: a genealogical approach. Genetics 160:741-751.

Camara, M. D., and B. Vadopalas. 2009. Genetic aspects of restoring Olympia oysters and other native bivalves: balancing good intentions, the need for action, and the risks of making things worse. Journal of Shellfish Research 28:121-145.

Caughley, G. 1994. Directions in conservation biology. Journal of Animal Ecology 63:215-244.

Charlesworth, D., and J. H. Willis. 2009. Fundamental concepts in genetics: the genetics of inbreeding depression. Nature Reviews Genetics 10:783-796.

Coyer, J. A., G., Hoarau, K. Sjøtun, and J. L. Olsen. 2008. Being abundant is not enough: a decrease in effective population size over eight generations in a Norwegian population of the seaweed, Fucus serratus. Biology Letters 4:755-757.

Crandall, K. A., D. Posada, and D. Vasco. 1999. Effective population sizes: missing measures and missing concepts. Animal Conservation 2:317-319.

Crow, J. F., and C. Denniston. 1988. Inbreeding and variance effective population numbers. Evolution 42:482-495.

England, P. R., J. M. Cornuet, P. Berthier, D. A Tallmon, and G. Luikart. 2006. Estimating effective population size from linkage disequilibrium: severe bias in small samples. Conservation Genetics 7:303-308.

Frankham, R. 1995. Effective population size adult population size ratios in wildlife -a review. Genetical Research 66:95-107.

Frankham, R. 2005. Genetics and extinction. Biological Conservation 126:131-140. 
Fraser, D. J., M. M. Hansen, S. Østergaard, N. Tessier, M. Legault, and L. Bernatchez. 2007. Comparative estimation of effective population sizes and temporal gene flow in two contrasting population systems. Molecular Ecology 16:3866-3889.

Garrigan, D., P. C. Marsh, and T. E. Dowling. 2002. Long-term effective population size of three endangered Colorado River fishes. Animal Conservation 5:95-102.

Gilpin, M. E., and M. E. Soulé. 1986. Minimum viable populations: the processes of species extinctions. Pages 13-34 in M. E. Soulé, editor. Conservation biology: the science of scarcity and diversity. Sinauer Associates, Sunderland, Massachusetts.

Hansen, M. M., and L. F. Jensen. 2005. Sibship within samples of brown trout (Salmo trutta) and implications for supportive breeding. Conservation Genetics 6:297-305.

Hansen, M. M., E. E. Nielsen, and K. D. Mensberg. 2006. Underwater but not out of sight: genetic monitoring of effective population size in the endangered North Sea houting (Coregonus oxyrhynchus). Canadian Journal of Fisheries and Aquatic Sciences 63:780-787.

Hauser, L., G. J. Adcock, P. J. Smith, J. H. B. Ramirez, and G. R. Carvalho. 2002. Loss of microsatellite diversity and low effective population size in an overexploited population of New Zealand snapper ( $\mathrm{Pa}$ grus auratus). Proceedings of the National Academy of Sciences 99:11742-11747.

Hauser, L., and G. R. Carvalho. 2008. Paradigm shifts in marine fisheries genetics: ugly hypotheses slain by beautiful facts. Fish and Fisheries 9:333-362.

Hedgecock, D., and K. Coykendall. 2007. Genetic risks of hatchery enhancement: the good, the bad, and the unknown. Pages 85-101 in T. M. Bert, editor. Ecological and genetic implications of aquaculture activities. Springer-Verlag, Dordrecht, The Netherlands.

Hedgecock, D., S. Launey, A. I. Pudovkin, Y. Naciri, S. Lapegue, and F. Bonhomme. 2007. Small effective number of parents $\left(N_{\mathrm{b}}\right)$ inferred from a naturally spawned cohort of juvenile European flat oysters Ostrea edulis. Marine Biology 150:1173-1182.

Hedrick, P. W., V. K. Rashbrook, and D. Hedgecock. 2000. Effective population size of winter-run chinook salmon based on microsatellite analysis of returning spawners. Canadian Journal of Fisheries and Aquatic Science 57:2368-2373.

Heled, J., and A. J. Drummond.2008. Bayesian inference of population size history from multiple loci. BMC Evolutionary Biology 8:289.

Hill, W. G. 1981. Estimation of effective population size from data on linkage disequilibrium. Genetical Research 38:209-216.

Hoarau, G., E. Boon, D. N. Jongma, S. Ferber, J. Palsson, H. W. Van Der Veer, A. D. Rijnsdorp, W. T. Stam, and J. L. Olsen. 2005. Low effective population size and evidence for inbreeding in an overexploited flatfish, plaice (Pleuronectes platessaL.). Proceedings of the Royal Society B 272:497-503.

Hutchinson, W. F., C. van Oosterhout, S. I. Rogers, and G. R. Carvalho. 2003. Temporal analysis of archived samples indicates marked genetic changes in declining North Sea cod (Gadus morbua). Proceedings of the Royal Society B 270:2125-2132.

Jorde, P. E., and N. Ryman. 1995. Temporal allele frequency change and estimation of effective size in populations with overlapping generations. Genetics 139:1077-1090.

Kuhner, M. K. 2006. LAMARC 2.0: maximum likelihood and Bayesian estimation of population parameters. Bioinformatics 22:768-770.

Kuhner, M. K. 2009. Coalescent genealogy samplers: windows into population history. Trends in Ecology \& Evolution 24:86-93.

Laikre, L., et al. 2010. Genetic diversity neglected in the implementation of the Convention on Biological Diversity. Conservation Biology 24:86-88.

Leber, K. M., S. Kitada, H. L. Blankenship, and T. Svåsand, editors. 2004. Stock enhancement and sea ranching: developments, pitfalls and opportunities. $2^{\text {nd }}$ edition. Blackwell, Oxford, United Kingdom.

Levins, R. A. 1969. Some demographic and genetic consequences of environmental heterogeneity for biological control. Bulletin of the Entomological Society of America 15:237-240.
Liu, Y., and J. E. Mittler. 2008. Selection dramatically reduces effective population size in HIV-1 infection. BMC Evolutionary Biology 8:133. DOI:10.1186/1471-2148-8-133.

Luikart, G., N. Ryman, D. A. Tallmon, M. K. Schwartz, and F. W. Allendorf. 2010. Estimation of census and effective population sizes: the increasing usefulness of DNA-based approaches. Conservation Genetics 11:355-373.

Lynch, M., and W. Gabriel. 1990. Mutation load and the survival of small populations. Evolution 44: 1725-1737.

Lynch, M., and R. Lande. 1998. The critical effective size for a genetically secure population. Animal Conservation 1:70-72.

Madsen, T., R. Shine, M. Olsson, and H. Wittzell. 1999. Restoration of an inbred adder population. Nature 402:34-35.

Miller, L. M., and A. R. Kapuscinski. 2003. Genetic guidelines for hatchery supplementation programs. Pages $329-355$ in E. Hallerman, editor. Population genetics: principles and practices for fisheries scientists. American Fisheries Society, Bethesda, Maryland.

Nei, M., and F. Tajima. 1981. Genetic drift and estimation of effective population size. Genetics 98:625-640.

Nunney, L. 1999. The effective size of a hierarchically-structured population. Evolution 53:1-10.

Nunney, L., and K. A. Campbell. 1993. Assessing minimum viable population size: demography meets population genetics. Trends in Ecology \& Evolution 8:234-239.

Olsen, E. M., M. Heino, G. R. Lilly, M. J. Morgan, J. Brattey, B. Ernande, and U. Dieckmann. 2004. Maturation trends indicative of rapid evolution preceded the collapse of northern cod. Nature 428:932935

Ovenden, J. R., D. Peel, R. Street, A. J. Courtney, S. D. Hoyle, S. L Peel, and $\mathrm{H}$. Podlich. 2007. The genetic effective and adult census size of an Australian population of tiger prawns (Penaeus esculentus). Molecular Ecology 16:127-138.

Palstra, F. P., and D. E. Ruzzante. 2008. Genetic estimates of contemporary effective population size: what can they tell us about the importance of genetic stochasticity for wild population persistence? Molecular Ecology 17:3428-3447.

Palstra, F., M. W. O'Connell, and D. E. Ruzzante. 2007. Population structure and gene flow reversals in Atlantic salmon (Salmo salar) over contemporary and long-term temporal scales: effects of population size and life history. Molecular Ecology 16:4504-4522.

Palstra, F. P., M. F. O'Connell, and D. E. Ruzzante. 2009. Age structure, changing demography and effective population size in Atlantic salmon (Salmo salar). Genetics 182:1233-1249.

Pollak, F. 1983. A new method for estimating the effective population size from allele frequency changes. Genetics 104:531-548.

Portnoy, D. S., J. R. McDowell, C. T. McCandless, J. A. Musick, and J. E. Graves. 2009. Effective size closely approximates the census size in the heavily exploited western Atlantic population of the sandbar shark, Carcharbinus plumbeus. Conservation Genetics 10:1697-1705.

Poulsen, N. A., E. E. Nielsen, M. H. Schierup, V. Loeschcke, and P. Gronkjaer. 2006. Long-term stability and effective population size in North Sea and Baltic Sea cod (Gadus morhua). Molecular Ecology 15:321-331.

Pudovkin, A. I., D. V. Zaykin, and D. Hedgecock. 1996. On the potential for estimating the effective number of breeders from heterozygoteexcess in progeny. Genetics 144:383-387.

Ruegg, K., E. C. Anderson, C. S. Baker, M. Vant, J. Jackson, and S. R. Palumbi.2010. Are Antarctic minke whales unusually abundant because of 20th century whaling?. Molecular Ecology 19:281291.

Ruzzante, D. E., S. J. Walde, J. C. Gosse, V. E. Cussac, E. Habit, T. S. Zemlak, and E. D. M. Adams. 2008. Climate control on ancestral population dynamics: insight from Patagonian fish phylogeography. Molecular Ecology 17:2234-2244.

Ryman, N., and L. Laikre. 1991. Effects of supportive breeding on the genetically effective population size. Conservation Biology 5:325-329. 
Saccheri, I. J., M. Kuussaari, M. Kankare, P. Vikman, W. Forteliusand, and I. Hanski. 1998. Inbreeding and extinctionin a butterfly metapopulation. Nature 392:491-494.

Saillant, E., and J. R. Gold. 2006. Population structure and variance effective size of red snapper (Lutjanus campechanus) in the Gulf of Mexico. Fishery Bulletin 104:136-148.

Santiago, E., and A. Caballero. 1995. Effective size of populations under selection. Genetics 139:1013-1030.

Schwartz, M. K., G. Luikart, and R. S. Waples. 2007. Genetic monitoring as a promising tool for conservation and management. Trends in Ecology \& Evolution 22:25-33.

Shapiro, B. et al. 2004. Rise and fall of the Beringian steppe bison. Science 306:1561-1565.

Shrimpton, J. M., and D. D. Heath. 2003. Census vs. effective population size in Chinook salmon: large- and small-scale environmental perturbation effects. Molecular Ecology 12:2571-2583.

Swain, D. P., A. F. Sinclair and J. M. Hanson. 2007. Evolutionary response to size-selective mortality in an exploited fish population. Proceedings of the Royal Society B 274:1015-1022.

Tallmon, D. A., A. Koyuk, G. Luikart, and M. A. Beaumont. 2008. ONeSAMP: a programto estimate effective population size using approximate Bayesian computation. Molecular Ecology Resources 8:299-301.

Tallmon, D. A., D. Gregovich, R. S. Waples, C. S. Baker, J. Jackson, B. L. Taylor, E. Archer, K. K. Martien, F. W. Allendorf, and M. K. Schwartz. 2010. When are genetic methods useful for estimating contemporary abundance and detecting population trends?. Molecular Ecology Resources 10:684-692.

Turner, T. F., M. J. Osborne, G. R. Moyer, M. A. Benavides, and D. Alo. 2006. Life history and environmental variation interact to determine effective population to census size ratio. Proceedings of the Royal Society B 273:3065-3073.

Vucetich, J. A., T. A. Waite, and L. Nunney. 1997. Fluctuating population size and the ratio of effective to census population size. Evolution 51:2017-2021.

Wang, J. 2005. Estimation of effective population sizes from data on genetic markers. Philosophical Transactions of the Royal Society, Series B: Biological Sciences 360:1395-1409.

Wang, J. 2009. A new method for estimating effective population sizes from a single sample of multilocus genotypes. Molecular Ecology 18:2148-2164.

Wang, J., and A. Caballero. 1999. Developments in predicting the effective size of subdivided populations. Heredity 82:212-226.
Wang, J., and N. Ryman. 2001. Genetic effects of multiple generations of supportive breeding. Conservation Biology 15:1619-1631.

Wang, J., and M. C. Whitlock. 2003. Estimating effective population size and migration rates from genetic samples over space and time. Genetics 163:429-446.

Waples, R. S. 1989. A generalized approach for estimating effective population size from temporal changes in allele frequency. Genetics 121:379-391.

Waples, R. S. 1991. Genetic methods for estimating the effective size of cetacean populations. Report of the International Whaling Commission (special issue 13):279-300.

Waples, R. S. 2005. Genetic estimates of contemporary effective population size: to what time periods do the estimates apply? Molecular Ecology 14:3335-3352.

Waples, R. S. 2010. Spatial-temporal stratifications in natural populations andhow they affect understanding and estimation of effective population size. Molecular Ecology Resources 10:785-796.

Waples, R. S., and C. Do. 1994. Genetic risk associated with supplementation of Pacific salmonids: captive broodstock programs. Canadian Journal of Fisheries and Aquatic Sciences 51(Supplement 1):310-329.

Waples, R. S., and C. Do. 2010. Linkage disequilibrium estimates of contemporary $N_{e}$ using highly variable genetic markers: a largely untapped resource for applied conservation and evolution. Evolutionary Applications 3:244-262.

Waples, R. S., and M. Yokota. 2007. Temporal estimates of effective population size in species with overlapping generations. Genetics 175:219-233.

Wares, J. P., and J. M. Pringle. 2008. Drift by drift: effective population size limited byadvection. BMC Evolutionary Biology 8:235. DOI:10.1186/1471-2148-8-235.

Whiteley, A. R., K. Hastings, J. K. Wenburg, C. A. Frissell, J. C. Martin, and F. W. Allendorf. 2010. Genetic variation and effective population size in isolated populations of coastal cutthroat trout. Conservation Genetics 11:1929-1943.

Whitlock, M. C., and N. H. Barton. 1997. The effective size of a subdivided population. Genetics 146:427-441.

Willi, Y., J. Van Buskirk, and A. A. Hoffmann. 2006. Limits to the adaptive potential of small populations. Annual Review of Ecology, Evolution, and Systematics 37:433-458.

Wright, S. 1931. Evolution in Mendelian populations. Genetics 16:97-159.

Wright, S. 1943. Isolation by distance. Genetics 28:114-138.

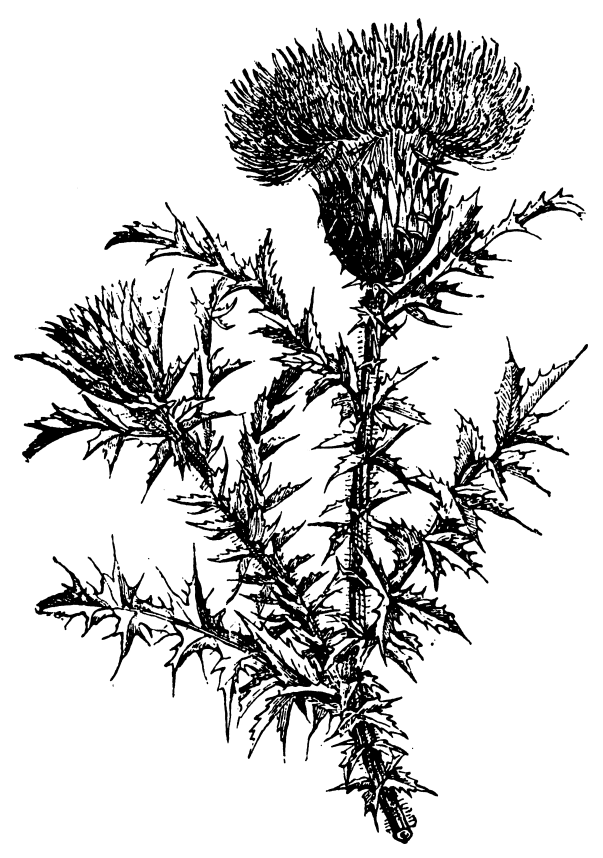

